\title{
PRECEDENTES JUDICIAIS E PADRÕES DECISÓRIOS: DA INTEGRIDADE E COERÊNCIA AO “GAP" DA TAXATIVIDADE MITIGADA DO ROL DO ARTIGO 1.015 DO CÓDIGO DE PROCESSO CIVIL ${ }^{1}$
}

\author{
JUDICIAL PRECEDENTS AND DECISION STANDARDS: FROM
} INTEGRITY AND COHERENCE TO THE MITIGATED TAXATIVENESS GAP OF THE LIST FROM THE ARTICLE 1.015 OF THE BRAZILIAN CIVIL PROCEDURE

\section{CODE}

\section{Débora Fernanda Ferreira}

Bacharel em Direito pela Universidade Federal de Lavras UFLA. Atuou como pesquisadora do Programa Institucional de Iniciação Científica Voluntária (PIVIC/UFLA). Membro e pesquisadora do Grupo de Estudos e Pesquisa em Processo Constitucional - GEPPROC/UFLA (Cadastro no Diretório Nacional de Grupos de Pesquisa - CNPq). São Roque de Minas/MG. E-mail: debora.ferreira@estudante.ufla.br

Fernanda Gomes e Souza Borges

Professora Adjunta de Direito Processual Civil do Departamento de Direito da Universidade Federal de Lavras UFLA. Doutora e Mestre em Direito Processual pela Pontifícia Universidade Católica de Minas Gerais - PUC/Minas. Coordenadora do Grupo de Estudos e Pesquisa em Processo Constitucional - GEPPROC/UFLA (Cadastro no Diretório Nacional de Grupos de Pesquisa - CNPq). Membro da ABDPro (Associação Brasileira de Direito Processual). Membro do IBDP (Instituto Brasileiro de Direito Processual). Membro da ABDPC (Associação Brasileira de Direito

\footnotetext{
${ }^{1}$ Artigo recebido em 31/08/2020 e aprovado em 03/11/2020.
} 


\title{
Processual Constitucional). Lavras/MG. E-mail: fernandagomes@ufla.br
}

RESUMO: O presente ensaio propõe-se a analisar os conceitos de precedentes judiciais e padrões decisórios visando, principalmente, contribuir para o debate doutrinário sobre a suposta existência de um "sistema de precedentes", inaugurado pelo CPC/2015, no ordenamento jurídico brasileiro. Oportunamente, faz-se também uma análise sobre o confronto entre os preceitos de integridade e coerência, preconizados pela teoria de Ronald Dworkin e presentes no CPC/2015, e a instabilidade jurídica causada por "gaps" decorrentes dos próprios padrões decisórios, como é o caso da taxatividade mitigada do rol do artigo 1.015 do CPC, analisando possíveis técnicas para superação dos problemas que possam advir dali.

PALAVRAS-CHAVE: Precedentes Judiciais. Padrões Decisórios. Integridade. Coerência. Taxatividade Mitigada.

\begin{abstract}
This essay aims to analyze the concepts of judicial precedents and decision standards aiming mainly to contribute to the doctrinal debate about the supposed existence of a "system of precedents", inaugurated by the Brazilian Civil Procedure Code of 2015, in the Brazilian legal system. Due to the course an analyse's made from confrontation between the precepts of integrity and coherence, advocated by the theory of Ronald Dworkin and present in Brazilian Civil Procedure Code of 2015, and the legal instability caused by gaps arising from the decision-making standards themselves, as the case of the mitigated taxativeness of the list from the article 1.015 of the Brazilian Civil Procedure Code of 2015, analyzing possible techniques to overcome the problems that may arise from there.
\end{abstract}

KEY WORDS: Judicial Precedents. Decision Standards. Integridy. Coherence. Mitigated Taxativeness. 


\section{INTRODUÇÃO}

Os cidadãos brasileiros vivem esperando o dia em que o direito será melhor. Anseiam um mundo mágico onde ter-se-ia mais segurança jurídica - aquela sensação consoladora de que casos semelhantes finalmente serão decididos de forma semelhante; anseiam, também, que a alta taxa de litigância repetitiva irá, finalmente, reduzir. Almejam um Judiciário rápido, justo e eficiente. E qual o problema disso? Bom, em tese, não há problema nenhum em tais anseios. O problema está, como diria o professor Lenio Streck $^{2}$, nas soluções encontradas para ele.

Está-se a falar de uma solução enfadonha e que vem prevalecendo no âmbito jurídicoprocessual nos últimos anos - o da existência do chamado "sistema de precedentes", supostamente inaugurado pelo Código de Processo Civil de 2015. Tal "sistema" estaria supostamente materializado no artigo 927 do CPC, de forma a instituir no ordenamento jurídico pátrio uma vinculação rígida às decisões prolatadas pelos tribunais superiores (com o fim, é claro, de ser uma solução confiável, digna e coerente para os problemas jurídicos supracitados).

Nesse ínterim, o que se questiona é: há, de fato, um sistema de precedentes no ordenamento jurídico brasileiro? Se existe, tal sistema afastou o Brasil da tradição romanogermânica e o aproximou da tradição anglo-saxã? Em que medida esse sistema contribui para a coerência e integridade da jurisprudência, a qual deverá ser alcançada pelos tribunais, conforme dispõe o artigo 926 do CPC? O propósito deste trabalho é desmitificar essa teoria. Para entender os erros dessa doutrina, será feita análise do que significa, de fato, precedente judicial, o que são os padrões decisórios (ou provimentos vinculantes) e, claro, a jurisprudência, termos usados muitas vezes de forma indistinta na prática forense.

Para além disso, será feita uma análise da incongruência existente entre os preceitos de coerência e integridade da jurisprudência, pressupostos almejados pelo CPC/2015, e os possíveis "gaps" decorrentes da própria padronização decisória. Para tal, será feita uma detida apreciação de um caso concreto, qual seja, o acórdão do REsp 1.704.520/MT - o qual estabeleceu que o rol das hipóteses de interposição do recurso de agravo de instrumento

\footnotetext{
${ }^{2}$ STRECK, Lenio Luiz. Precedentes judiciais e hermenêutica. $2^{\mathrm{a}}$ edição. Salvador: JusPodivm, 2019. p. 9.
} 
(artigo 1.015 do CPC) admite interpretação extensiva e, portanto, possui a natureza de "taxatividade mitigada".

O supracitado julgado, por tratar-se de um acórdão prolatado em sede de recurso especial repetitivo, está elencado no rol dos padrões decisórios do artigo 927 e, dessa forma, deverá ser observado e seguido pelos tribunais de todo o país. O objetivo deste artigo é, destarte, compreender os desafios na busca pela segurança jurídica ${ }^{3}$, a partir do manejo dos padrões decisórios pelos tribunais, e constatar técnicas para solucionar os problemas que, inevitavelmente, poderão emergir.

\section{CONCEITOS ESSENCIAIS}

Para a compreensão do que (não) seria o "sistema de precedentes" contido no CPC/2015, é necessário entender, inicialmente, os conceitos básicos (e muito confundidos), de precedentes judiciais, padrões decisórios (também chamados de "provimentos vinculantes" ou “instrumentos de vinculação decisória”) e, claro, jurisprudência.

\subsection{PRECEDENTES JUDICIAIS}

O termo "precedente" é corriqueiramente utilizado para tratar o que, na verdade, se denomina “jurisprudência”. Ressalta-se que, inclusive, os termos são utilizados muitas vezes como se sinônimos fossem - o que, como será demonstrado a seguir, é um grande equívoco. A primeira diferença existente entre precedente e jurisprudência consiste na quantidade precedente é apenas uma decisão judicial, relativa a um caso particular, ao passo que a jurisprudência consiste em uma pluralidade de decisões relativas aos mais diversos casos ${ }^{4}$.

Podemos compreender o precedente, destarte, como uma decisão de um tribunal que possui aptidão de vir a ser reproduzida pelos tribunais inferiores mas que, nada obstante, só poderá obter a condição de precedente na medida em que vier a ser efetivamente seguida na

\footnotetext{
${ }^{3}$ Ressalta-se que, em que pese o fato de que conceito de "segurança jurídica" carrega consigo uma "carga positivista" e se contrapõe, dessa forma, à teoria de Ronald Dworkin, optou-se aqui por emprega-lo no decorrer do presente trabalho em razão da frequente utilização do mesmo na doutrina e na jurisprudência, inclusive, com a pretensão de justificar a existência do suposto "sistema de precedentes".

${ }^{4}$ TARUFFO, Michele. Precedente e jurisprudência. Trad. Chiara de Teffé. Civilistica.com. Rio de Janeiro, a. 3, n. 2, jul.-dez./2014. p. 3.
} 
resolução de casos análogos ${ }^{5}$. Constata-se, a partir desse entendimento, um ponto importante, inclusive, para a crítica à doutrina que preconiza a existência de um "sistema de precedentes" no CPC/2015: um precedente não "nasce" precedente mas, sim, torna-se na medida em que os juízes dos tribunais inferiores decidirem pela aplicação ou não de tal decisão no caso concreto.

A doutrina do "stare decisis", presente no sistema jurídico do common law, preconiza que os precedentes, estes compreendidos como decisões de tribunais reiteradas ou não, vinculam julgamentos futuros que tratam da mesma matéria ${ }^{6}$. Destarte, ressalta-se que, no que tange a tradição anglo-saxã, a vinculação dos precedentes não decorre diretamente da lei mas, sim, da construção histórica, que decorreu na mudança da forma de atuação dos órgãos jurisdicionais ${ }^{7}$, sendo este, também, mais um ponto de diferenciação do sistema que recentemente se pretendeu aqui introduzir através de alterações legislativas e o sistema existente há séculos no common law.

Impende, no que tange aos precedentes, salientar ainda que, para manejo e aplicação dos mesmos, é indispensável a identificação, através de detida apreciação da decisão judicial relativa ao caso concreto, do que se trata de ratio decidendi e obiter dictum. A ratio decidendi, ou seja, a "razão de decidir", pode ser compreendida como a regra de direito que fora utilizada como fundamento direto da decisão sobre os fatos específicos do caso concreto $^{8}$. Nesse sentido, sendo a ratio decidendi pode ser explicada, também, como um enunciado jurídico a partir do qual o caso concreto é decidido, de forma que esta possui como função evitar arbitrariedades nas decisões judiciais ${ }^{9}$.

O obiter dictum, por sua vez, corresponde ao fragmento contido na decisão judicial que se mostra irrelevante, no que tange ao conteúdo e presença, para a solução final do caso $^{10}$. Destarte, mostra-se evidente que a dificuldade, no que tange a análise da decisão

\footnotetext{
${ }^{5}$ STRECK, Lenio. ABBOUD, Georges. O que é isto - o precedente judicial e as súmulas vinculantes? $3^{\mathrm{a}}$ edição. Porto Alegre: Livraria do Advogado Editora, 2015. p. 46.

${ }^{6}$ NOGUEIRA, Gustavo Santana. Stare decisis et non quieta movere: a vinculação aos precedentes no direito comparado e brasileiro. Rio de Janeiro: Lumen Juris, 2011. p. 1.

${ }^{7}$ CÂMARA, Alexandre Freitas. Levando os padrões decisórios a sério. $1^{a}$ edição. São Paulo: Atlas, 2018. p. 19.

${ }^{8}$ TARUFFO, Michele. Precedente e jurisprudência. Trad. Chiara de Teffé. Civilistica.com. Rio de Janeiro, a. 3, n. 2, jul.-dez./2014. p. 6.

${ }^{9}$ STRECK, Lenio. ABBOUD, Georges. O que é isto - o precedente judicial e as súmulas vinculantes? $3^{\mathrm{a}}$ edição. Porto Alegre: Livraria do Advogado Editora, 2015. p. 47-48.

${ }^{10}$ STRECK, Lenio. ABBOUD, Georges. O que é isto - o precedente judicial e as súmulas vinculantes? $3^{\mathrm{a}}$ edição. Porto Alegre: Livraria do Advogado Editora, 2015. p. 48.
} 
judicial que poderá vir a ser utilizada como precedente, consiste em determinar o que de fato é o fundamento para a decisão, ou seja, no que consiste a ratio decidendi, e que todo o resto do conteúdo presente na decisão se trata meramente de obiter dictum e, portanto, consiste em argumentos prescindíveis para a solução da lide ${ }^{11}$.

Por fim, constatado o conceito e a forma de aplicação do precedente judicial, observase que não é possível uma aplicação automática (subsuntiva) ou mesmo mecânica de tal instituto, isso porque não há uma prévia regra jurídica pronta e apta para solucionar diversos casos futuros por efeito cascata ${ }^{12}$. Aliás, o contrário é verdadeiro, pois o próprio precedente, que consiste em uma regra jurídica, é fruto de intenso debate e atividade interpretativa e, após a sua localização, passa-se a verificar se nas circunstâncias do caso concreto que se analisa ele poderá vir a ser utilizado sem que ocorra graves distorções; no caso de estas ocorrem, o precedente deverá ser necessariamente afastado ${ }^{13}$.

\subsection{JURISPRUDÊNCIA}

Como visto, a jurisprudência se difere do precedente pois aquela diz respeito a um conjunto de decisões judiciais relativas a casos concretos diversos, ao passo em que este consiste em apenas uma decisão relativa a um único caso concreto. Essa diferença no que tange a "quantidade" acarreta obstáculos, tais como a dificuldade em determinar qual decisão é realmente relevante ou até mesmo quantas decisões são necessárias para que se tenha uma jurisprudência formada sobre a interpretação de determinada norma ${ }^{14}$.

Como outrora analisado, o precedente determina uma regra jurídica aplicável a determinado caso concreto, a qual poderá vir a ser utilizada como fundamento para a decisão de casos similares. A análise para verificar a possibilidade de aplicação futura pauta-se, principalmente, na detida apreciação dos fatos do caso que motivou a decisão que poderá vir

11 STRECK, Lenio Luiz; RAATZ, Igor; MORBACH, Gilberto. Da complexidade à simplificação na identificação da ratio decidendi: será mesmo que estamos a falar de precedentes no Brasil? Revista Jurídica Unicuritiba. Curitiba, v. 01, nº 54, 2019. p. 320.

${ }^{12}$ STRECK, Lenio. ABBOUD, Georges. O que é isto - o precedente judicial e as súmulas vinculantes? $3^{\mathrm{a}}$ edição. Porto Alegre: Livraria do Advogado Editora, 2015. p. 50.

${ }^{13}$ STRECK, Lenio. ABBOUD, Georges. O que é isto - o precedente judicial e as súmulas vinculantes? $3^{\mathrm{a}}$ edição. Porto Alegre: Livraria do Advogado Editora, 2015. p. 50.

${ }^{14}$ TARUFFO, Michele. Precedente e jurisprudência. Trad. Chiara de Teffé. Civilistica.com. Rio de Janeiro, a. 3, n. 2, jul.-dez./2014. p. 3. 
a ser utilizada como precedente - a decisão só será utilizada na medida em que ocorra identidade entre os fatos do caso futuro e do caso paradigma; além disso, há, também, a necessidade de se constatar a possibilidade de aplicação da ratio decidendi do precedente no caso em tela.

Em se tratando de jurisprudência a aplicação ocorre de maneira diversa, uma vez que há ausência da análise comparativa dos fatos na maior parte dos $\operatorname{casos}^{15}$. Isso porque a jurisprudência, na tradição romano-germânica, funciona como uma consolidação de teses gerais e abstratas, mais específicas que a lei, sobre determinado assunto, de modo que a análise dos fatos dos casos concretos integrantes do conjunto de decisões que formaram a jurisprudência não é realizada. Destarte, em regra, não há a inclusão dos fatos do caso que fora objeto de decisão nos textos que constituem a jurisprudência nos ordenamentos jurídicos da tradição do civil law, de modo que a aplicação da regra firmada em sede de jurisprudência não é baseada na analogia dos fatos mas, sim, da subsunção da chamada "fattispecie" a uma regra geral ${ }^{16}$.

Demonstra-se, pois, que a aplicação da jurisprudência se difere e muito da aplicação dos precedentes e, para além disso, fica constatado, também, a dificuldade existente na averiguação da existência ou não de uma jurisprudência, uma vez que não há um número determinado de decisões para que se possa considerar que uma jurisprudência foi, de fato, formada. Para além disso, levando em consideração a existência de uma alta taxa de litigância em nosso país, tendo em vista que apenas no Supremo Tribunal Federal (STF) no ano de 2019 foram proferidas 115.877 decisões ${ }^{17}$, constata-se, também, a dificuldade oriunda do grande número de decisões prolatadas e da possibilidade de existência de decisões contraditórias entre si.

\subsection{PADRÕES DECISÓRIOS}

15 TARUFFO, Michele. Precedente e jurisprudência. Trad. Chiara de Teffé. Civilistica.com. Rio de Janeiro, a. 3, n. 2, jul.-dez./2014. p. 4.

${ }^{16}$ TARUFFO, Michele. Precedente e jurisprudência. Trad. Chiara de Teffé. Civilistica.com. Rio de Janeiro, a. 3, n. 2, jul.-dez./2014. p. 5.

BRASIL.
17 Estatísticas do STF.

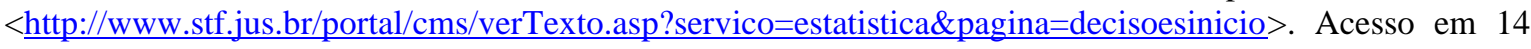
de jul. 2020. 
O rol do artigo 927 do $\mathrm{CPC} / 2015^{18}$ estabeleceu uma série de instrumentos de vinculação decisória, também denominados de provimentos vinculantes, que aqui chamamos de "padrões decisórios", a mesma denominação dada pelo professor Alexandre Freitas Câmara ${ }^{19}$, levando em consideração que esta é a expressão empregada pelo próprio CPC na redação do $\S 5^{\circ}$ do artigo 966 . Destarte, feita a distinção entre precedentes judiciais e jurisprudência, passamos a compreender o que de fato são os provimentos elencados no artigo 927 do Código de Processo Civil de 2015.

Os padrões decisórios consistem em decisões judiciais, acórdãos e enunciados de súmula que "deverão", segundo o texto do próprio CPC, ser observados pelos juízes e tribunais de todo o país. Dentre os padrões decisórios elencados no artigo 927, destaca-se que há uma distinção entre os padrões vinculantes e padrões persuasivos (argumentativos). O ponto central da distinção consiste no grau e na forma como é desenvolvido o princípio do contraditório na formação de cada uma das decisões, acórdãos e súmulas. Destarte, o modo como se desenvolve o contraditório em cada um dos procedimentos é o que vem a determinar a atribuição expressa de eficácia vinculante para alguns dos deles, de modo que estes podem vir a ser denominados de padrões decisórios (formalmente) vinculantes, ao passo em que outros não possuem esta eficácia vinculante expressamente estabelecida, motivo pelo qual são denominados de padrões decisórios (meramente) persuasivos ou $\operatorname{argumentativos}^{20}$.

Nesse sentido, elucida-se que as decisões do Supremo Tribunal Federal (STF) em controle direto de constitucionalidade (art. 102, $2^{\circ}, \mathrm{CF} / 88$ ) e os enunciados de súmula vinculante (art. 103-A, CF/88), referidos nos incisos I e II do artigo 927 do CPC, possuem eficácia vinculante por força da própria constituição. Além desses, o CPC atribui efeito vinculante, também, aos acórdãos de incidente de assunção de competência (art. 947, $\S 3^{\circ}$,

\footnotetext{
${ }^{18}$ Art. 927. Os juízes e os tribunais observarão: I - as decisões do Supremo Tribunal Federal em controle concentrado de constitucionalidade; II - os enunciados de súmula vinculante; III - os acórdãos em incidente de assunção de competência ou de resolução de demandas repetitivas e em julgamento de recursos extraordinário e especial repetitivos; IV - os enunciados das súmulas do Supremo Tribunal Federal em matéria constitucional e do Superior Tribunal de Justiça em matéria infraconstitucional;

$\mathrm{V}$ - a orientação do plenário ou do órgão especial aos quais estiverem vinculados.

${ }^{19}$ CÂMARA, Alexandre Freitas. Levando os padrões decisórios a sério. $1^{a}$ edição. São Paulo: Atlas, 2018. p. 1.

${ }^{20}$ CÂMARA, Alexandre Freitas. Levando os padrões decisórios a sério. $1^{\text {a }}$ edição. São Paulo: Atlas, 2018. p. 180 .
} 
CPC), de incidentes de resolução de demanda repetitiva (art. 985, CPC), bem como os acórdãos de recursos especiais e extraordinários repetitivos (art. 1.040, CPC) ${ }^{21}$.

Outrossim, aos enunciados de súmula do Supremo Tribunal Federal (STF) em matéria constitucional, os enunciados de súmula do Superior Tribunal de Justiça (STJ) em matéria infraconstitucional e as orientações do plenário ou do órgão especial de cada tribunal, é conferida uma vinculação meramente persuasiva. Isso ocorre, pois, a amplitude do contraditório nessas hipóteses supracitadas é bem menor do que nos outros procedimentos, aos quais fora conferida a vinculação ${ }^{22}$.

Os padrões decisórios não vinculantes ou argumentativos devem ser levados em conta pelos magistrados no momento de proferir os acórdãos e decisões e só podem ser afastados quando houver algum argumento novo no processo, ainda não submetido à discussão no tribunal superior ${ }^{23}$. Os padrões decisórios vinculantes, ao seu turno, só podem vir a ser afastados quando ficar demonstrado que os casos são diferentes através da técnica do distinguishing, ou quando o próprio tribunal responsável pela fixação do padrão decisório já não o emprega mais, por meio da utilização da técnica do overruling, como se verá mais adiante ${ }^{24}$.

Essa compreensão dos padrões decisórios demonstra o quão necessário se faz o "ônus argumentativo" no manejo dos mesmos, pois o órgão jurisdicional que decide de modo diverso de padrão decisório já estabelecido possui o ônus de confrontar o novo caso com aqueles que deram origem ao padrão decisório, de forma a constatar que o argumento que agora se emprega não fora outrora examinado e rejeitado pelos pronunciamentos que vieram a decorrer na fixação do padrão decisório em análise ${ }^{25}$.

Prosseguindo, importante observar que proposta de distinção entre padrões vinculantes e argumentativos, diretamente ligada à amplitude do contraditório, repousa em duas premissas. A primeira consiste na "comparticipação subjetivamente ampliada", de

\footnotetext{
${ }^{21}$ CÂMARA, Alexandre Freitas. Levando os padrões decisórios a sério. $1^{a}$ edição. São Paulo: Atlas, 2018. p. 182.

${ }^{22}$ CÂMARA, Alexandre Freitas. Levando os padrões decisórios a sério. $1^{a}$ edição. São Paulo: Atlas, 2018. p. 182.

${ }^{23}$ CÂMARA, Alexandre Freitas. Levando os padrões decisórios a sério. $1^{\text {a }}$ edição. São Paulo: Atlas, 2018. p. 284.

${ }^{24}$ CÂMARA, Alexandre Freitas. Levando os padrões decisórios a sério. $1^{a}$ edição. São Paulo: Atlas, 2018. p. 284.

${ }^{25}$ CÂMARA, Alexandre Freitas. Levando os padrões decisórios a sério. $1^{\text {a }}$ edição. São Paulo: Atlas, 2018. p. 286.
} 
forma a qualificar os padrões decisórios como vinculantes; a segunda, por sua vez, trata-se da "forma qualificada de deliberação por parte dos órgãos jurisdicionais" ${ }^{26}$. Essa exigência de contraditório diferenciado justifica-se pois os padrões decisórios vinculantes possuem força para alcançar, inclusive, pessoas que não fizeram parte do processo no qual fora proferido o acórdão, decisão ou enunciado de súmula que as vinculará ${ }^{27}$.

Destarte, entre os mecanismos adotados para a ampliação do contraditório e a garantia de participação com influência na construção da decisão judicial destaca-se, notavelmente, a participação do amicus curiae no processo e a realização de audiências públicas $^{28}$. Tais mecanismos são cruciais para garantir a representatividade adequada no processo, ou seja, são instrumentos que garantem uma necessária abertura para a participação da sociedade no processo de formação dos padrões decisórios que irão vincular, inclusive, aqueles que não fizeram diretamente parte do processo, de forma a não violar a garantia do devido processo legal ${ }^{29}$.

Por fim, no que tange a deliberação qualificada, ressalta-se que essa exigência emerge justamente da necessidade de se determinar a ratio decidendi do padrão decisório os fundamentos determinantes de um padrão decisório dotado de eficácia vinculante deverão, necessariamente, ser proferidos pela unanimidade de um órgão colegiado; além disso, o órgão jurisdicional tem o dever, também, de enfrentar todos os argumentos trazidos ao processo por todos os participantes, inclusive os amici curiae e aqueles abordados nas audiências públicas ${ }^{30}$.

Observa-se ainda que, no que tange ao sistema de deliberação, a maioria deverá ser qualificada, fazendo-se, portanto, necessário que haja consenso entre os julgadores quanto aos fundamentos que motivaram a decisão ${ }^{31}$. Explico: é necessário que a maioria dos magistrados adotem, em seus votos, os mesmos fundamentos para justificar a procedência

${ }^{26}$ CÂMARA, Alexandre Freitas. Levando os padrões decisórios a sério. $1^{\mathrm{a}}$ edição. São Paulo: Atlas, 2018. p. 182.

${ }^{27}$ CÂMARA, Alexandre Freitas. Levando os padrões decisórios a sério. $1^{a}$ edição. São Paulo: Atlas, 2018. p. 184.

${ }^{28}$ CÂMARA, Alexandre Freitas. Levando os padrões decisórios a sério. $1^{\text {a }}$ edição. São Paulo: Atlas, 2018. p. 185.

${ }^{29}$ CÂMARA, Alexandre Freitas. Levando os padrões decisórios a sério. $1^{\text {a }}$ edição. São Paulo: Atlas, 2018. p. 191.

${ }^{30}$ CÂMARA, Alexandre Freitas. Levando os padrões decisórios a sério. $1^{\text {a }}$ edição. São Paulo: Atlas, 2018. p. 267-268.

${ }^{31}$ CÂMARA, Alexandre Freitas. Levando os padrões decisórios a sério. $1^{a}$ edição. São Paulo: Atlas, 2018. p. 256-264. 
ou não do pedido; destarte, não é admissível como padrão decisório a decisão na qual, por exemplo, embora a maioria dos magistrados tenham votado pela procedência do pedido, os fundamentos dos votos proferidos são distintos e não configuram a maioria qualificada.

\section{AFINAL, EXISTE UM SISTEMA DE PRECEDENTES NO CPC/2015?}

Ante todo o exposto, acreditamos restar claro que não há, de fato, um "sistema de precedentes" estabelecido no Código de Processo Civil de 2015. Tal constatação se mostra cristalina a partir do momento em que analisamos o conceito de precedente, restando demonstrado que a utilização de mecanismos de vinculação decisória no Brasil se afasta (e muito) da aplicação original dos precedentes na tradição anglo-saxã.

Observa-se que, na tradição anglo-saxã os precedentes não são construídos para, a partir de teses, vincular o julgamento de casos futuros ${ }^{32}$. Como outrora explicado, o precedente não nasce com a pretensão de vincular casos futuros, pelo contrário, ele só vinculará na hipótese em que o juiz do caso posterior entender que as razões de decidir do precedente poderão vir a ser aplicadas ao caso futuro, ou seja, o precedente vincula, na tradição anglo-saxã, de forma contingencial.

Além disso, a existência de tal sistema de precedentes no ordenamento jurídico brasileiro seria, indubitavelmente, inconstitucional, tendo em vista que, de acordo com os artigos 102 e 105 da Constituição de 1988, os tribunais brasileiros julgam "causas" e não "teses" 33 , para além do fato de que uma lei ordinária não poderia alterar todo o sistema jurídico do Brasil sem afrontar a ordem democrático-constitucional ${ }^{34}$.

Outrossim, o papel central que os defensores da tese do "sistema de precedentes" conferem ao Poder Judiciário afronta diretamente a função do Poder Legislativo, além de que o status conferido aos provimentos emanados pelo Judiciário é feito sem nem mesmo explicar o porquê, de fato, o precedente seria melhor que a própria lei ${ }^{35}$. Ademais, observarse que não é possível sustentar a tese de que existira "cortes supremas" no Brasil, as quais deteriam o poder de firmar teses com a única interpretação correta para determinada questão

\footnotetext{
${ }^{32}$ STRECK, Lenio Luiz. Precedentes judiciais e hermenêutica. $2^{\mathrm{a}}$ edição. Salvador: JusPodivm, 2019. p. 22.

${ }^{33}$ STRECK, Lenio Luiz. Precedentes judiciais e hermenêutica. $2^{\text {a }}$ edição. Salvador: JusPodivm, 2019. p. 23.

${ }^{34}$ STRECK, Lenio Luiz. Precedentes judiciais e hermenêutica. $2^{\text {a }}$ edição. Salvador: JusPodivm, 2019. p. 97.

${ }^{35}$ STRECK, Lenio Luiz. Precedentes judiciais e hermenêutica. $2^{\text {a }}$ edição. Salvador: JusPodivm, 2019. p. 32.
} 
jurídica, como advogam os defensores da tese dos precedentes, isto porque não é possível que exista uma única interpretação correta para a ratio decidendi de um caso concreto, ou seja, a regra de direito posta como fundamento na decisão do caso concreto é aberta à intepretação, tendo em vista o dever da construção comparticipada da decisão de casos sucessivos, razão pela qual não se pode cogitar na possibilidade de proibição da interpretação do próprio precedente ${ }^{36}$.

Nesse sentido, ressalta-se que, em que pese a existência dos padrões decisórios vinculantes a partir do CPC/2015, a existência de mecanismos de vinculação decisória não é novidade em nosso ordenamento jurídico, tendo em vista que já nos idos dos anos de 1850 , com o Decreto $n^{\circ} 738$, surgiram os chamados "assentos", semelhantes aos enunciados de súmula, os quais possuíam, à época, eficácia vinculante ${ }^{37}$. Já na década de 1960 surgiram as súmulas da jurisprudência dominante do STF, de forma bastante semelhante as que temos ainda hoje, as quais nasceram da "falta de memória" do Ministro Victor Nunes Leal ${ }^{38}$. Destarte, não há o que se falar em uma mudança de paradigma com a promulgação do CPC/2015, que traz consigo a pretensão da vinculação através de padrões decisórios, uma vez que desde o Direito do Império e do Direito português anterior já existia uma valorização intensa da jurisprudência e dos precedentes no Brasil ${ }^{39}$.

Apesar dessa longa história de vinculação através de decisões judiciais e súmulas, o problema da segurança jurídica aparentemente ainda não fora solucionado (caso contrário, não seria necessário todo o rol de padrões decisórios dispostos no art. 927). Isso porque a ausência de segurança jurídica na jurisprudência brasileira está atrelada ao descompromisso do Judiciário pátrio com a legalidade, tendo em vista a compreensão dos magistrados de que a lei estaria à disposição do intérprete, o qual poderia deixar de aplica-la por razões de conveniência ${ }^{40}$.

\footnotetext{
${ }^{36}$ VIANA, Antônio Aurélio de Souza Viana. Precedentes vinculantes e cortes supremas: uma análise crítica. Teoria Jurídica Contemporânea. Rio de Janeiro, v. 1, n. 2, jul-dez 2016. p. 2.

${ }^{37}$ CÂMARA, Alexandre Freitas. Levando os padrões decisórios a sério. $1^{\text {a }}$ edição. São Paulo: Atlas, 2018. p. 116.

${ }^{38}$ CÂMARA, Alexandre Freitas. Levando os padrões decisórios a sério. $1^{\text {a }}$ edição. São Paulo: Atlas, 2018. p. $118-120$.

${ }^{39}$ DIDIER JR, Fredie. SOUZA, Marcus Seixas. O respeito aos precedentes como diretriz histórica do direito brasileiro. Revista de Processo Comparado. Ano 1, vol. 2, jul.-dez. 2015. p. 106

${ }^{40}$ STRECK, Lenio. ABBOUD, Georges. O que é isto - o precedente judicial e as súmulas vinculantes? $3^{\mathrm{a}}$ edição. Porto Alegre: Livraria do Advogado Editora, 2015. p. 116.
} 
A vinculação, formalmente considerada, não é a solução em si para o problema da segurança jurídica. Os padrões decisórios deverão ser valorizados não pela força vinculante que possuem, mas, sim, por serem o ponto de partida da construção da história institucional sobre a interpretação de determinada norma. Em outras palavras, a fixação dos padrões decisórios não deverá ser vislumbrada como o "fim da história", mas, sim, como um principium a partir do qual será desenvolvida a história institucional da matéria enfrentada ${ }^{41}$.

E, já que restou demonstrado que a vinculação não salvará os cidadãos da insegurança jurídica, qual a melhor solução jurídica para o supracitado problema? Para responder essa indagação é necessário compreender o que dispõe o artigo 926 do CPC/2015 e qual o significado dos conceitos de coerência e integridade no âmbito da teoria de Ronald Dworkin.

\subsection{COERÊNCIA E INTEGRIDADE PARA QUÊ?}

O artigo 926 do CPC/2015 dispõe que "os tribunais devem uniformizar sua jurisprudência e mantê-la estável, íntegra e coerente". Mas, afinal, no que consiste esse dever de integridade e coerência? Por quê, de fato, ele deve ser respeitado? Basicamente, dizer que existe um dever de manter a jurisprudência íntegra e coerente é o mesmo que dizer que em se tratando de casos semelhantes, deverá ser proporcionada a garantia da isonômica aplicação principiológica ${ }^{42}$.

A coerência ocorre no caso concreto na medida em que se aplica os mesmos preceitos e princípios utilizados nas decisões para casos idênticos ${ }^{43}$. Destarte, a coerência assegura a igualdade de tratamento entre casos semelhantes. Outrossim, a integridade, por sua vez, é o dever imposto aos juízes de construir os seus argumentos de forma integrada ao conjunto do direito, consistindo, dessa forma, em uma garantia contra arbitrariedades interpretativas;

\footnotetext{
${ }^{41}$ CÂMARA, Alexandre Freitas. Levando os padrões decisórios a sério. $1^{\text {a }}$ edição. São Paulo: Atlas, 2018. p. 277.

${ }^{42}$ STRECK, Lenio. ABBOUD, Georges. O que é isto - o precedente judicial e as súmulas vinculantes? $3^{\text {a }}$ edição. Porto Alegre: Livraria do Advogado Editora, 2015. p. 117.

${ }^{43}$ STRECK, Lenio. ABBOUD, Georges. O que é isto - o precedente judicial e as súmulas vinculantes? $3^{\mathrm{a}}$ edição. Porto Alegre: Livraria do Advogado Editora, 2015. p. 117.
} 
nesse sentido, a exigência do dever de integridade impede que práticas ativistas, voluntaristas e discricionárias ocorram contra os jurisdicionados ${ }^{44}$.

O dever de coerência e integridade está diretamente ligado, também, à exigência de que o magistrado, ao prolatar uma decisão, deverá dialogar diretamente com as decisões anteriores $^{45}$. Destarte, a autorreferência nas decisões judiciais pode ser explicada através da metáfora do "romance em cadeia" (chain romance) de Ronald Dworkin, o qual afirma que ao decidir o novo caso, cada juiz deve considerar-se como parceiro de um complexo empreendimento em cadeia, do qual essas inúmeras decisões, estrutura, convenções e práticas são a história; é seu trabalho continuar essa história no futuro por meio do que ele faz agora. Ele deve interpretar o que aconteceu antes porque tem a responsabilidade de levar adiante a incumbência que tem em mãos e não partir em alguma nova direção. Portanto, deve determinar, segundo seu próprio julgamento, o motivo das decisões anteriores, qual realmente é, tomado como um todo, o propósito ou tema da prática até então (DWORKIN, 2005, p. 238).

O dever de autorreferência pode ser compreendido, também, como o dever de respeitar a história institucional de determinado tribunal ao decidir sobre determinado tema de forma a ensejar um padrão decisório ${ }^{46}$, o que é uma materialização clara da disposição do artigo 926 do CPC, além de corroborar a doutrina do direito como integridade de Ronald Dworkin, o qual dispõe que o juiz deve se considerar como um autor na cadeia do direito, de forma a constatar que outros magistrados decidiram, também, casos semelhantes ao seu, e que cabe a ele o dever de considerar as decisões outrora proferidas, decidindo de forma a dar o melhor andamento possível para a história ${ }^{47}$.

É, portanto, através do respeito aos preceitos de coerência e integridade, de forma a corroborar a história institucional através da padronização decisória, que poderão os cidadãos brasileiros sonhar com uma maior segurança jurídica. Nesse sentido, para além do necessário grau de previsibilidade que deve ser esperada das decisões judicias, é preciso

\footnotetext{
${ }^{44}$ STRECK, Lenio. ABBOUD, Georges. O que é isto - o precedente judicial e as súmulas vinculantes? $3^{\mathrm{a}}$ edição. Porto Alegre: Livraria do Advogado Editora, 2015. p. 118.

${ }^{45}$ CÂMARA, Alexandre Freitas. Levando os padrões decisórios a sério. $1^{a}$ edição. São Paulo: Atlas, 2018. p. 291.

${ }^{46}$ CÂMARA, Alexandre Freitas. Levando os padrões decisórios a sério. $1^{a}$ edição. São Paulo: Atlas, 2018. p. 291.

${ }^{47}$ DWORKIN, Ronald. O império do direito. Trad. Bras. Jefferson Luiz Camargo. São Paulo: Martins Fontes, 1999. p. 286.
} 
constatar que não há maior segurança jurídica do que a certeza que a atividade jurisdicional será exercida de forma a respeitar os princípios da tradição jurídico-institucional ${ }^{48}$.

Destarte, observa-se que a vinculação, formalmente considerada, não é suficiente para resolver os problemas da praxe forense brasileira, uma vez que há muito se trabalha com a vinculação no ordenamento jurídico pátrio, inclusive através da criação de súmulas vinculantes - é apenas através do respeito dos deveres de integridade e coerência e dos princípios democráticos constitucionalmente assegurados que encontrar-se-á segurança jurídica.

Ademais, em que pese a utilização benéfica da padronização decisória, esta poderá, infelizmente, vir a ser utilizada de maneira equivocada, podendo, inclusive, romper com o romance em cadeia e infringir na violação dos deveres de integridade e coerência. Por todo o exposto, entende-se que esse é o caso do REsp no 1.704.520/MT, o qual será analisado em seguida.

\section{0 “GAP” DA TAXATIVIDADE MITIGADA DO ROL DO ARTIGO 1.015 DO CPC: UMA ANÁLISE DO ACÓRDÃO DO RESP 1.704.520/MT}

Como outrora tratado, a utilização de precedentes e o manejo de padrões decisórios enfrenta diversas dificuldades no Brasil. Podemos citar como uma delas o fato de que, ao tratar de decisões anteriores, os tribunais utilizam, principalmente, o número dos recursos. Destarte, o manejo é muito diferente do que o que ocorre na tradição anglo-saxã pois enquanto nesta tradição os precedentes são tratados como caso, sendo mencionado, inclusive, o nome das partes nele envolvidas, na tradição romano-germânica os precedentes são vistos como número de processos julgados pelos tribunais, ou seja, são transformados em uma espécie de "conceito sem coisa"49.

Enquanto na tradição do common law os tribunais, ao fazer o manejo dos precedentes, preocupam-se principalmente com as situações fáticas do caso, aqui no Brasil acontece um fenômeno distinto - os tribunais preocupam-se muito mais com a "tese jurídica firmada" no julgamento de um recurso $X$, do que com a situação fática do julgado. É devido a essa praxe

${ }^{48}$ STRECK, Lenio Luiz. Precedentes judiciais e hermenêutica. $2^{\mathrm{a}}$ edição. Salvador: JusPodivm, 2019. p. 153.

${ }^{49}$ STRECK, Lenio Luiz. Precedentes judiciais e hermenêutica. $2^{\text {a }}$ edição. Salvador: JusPodivm, 2019. p. 42. 
jurídica brasileira que muitas das vezes um acórdão é utilizado como fundamento de uma decisão sem que ao menos seja feita a análise de compatibilidade entre as situações fáticas do acórdão e o caso a ser decidido.

Impende, pois, ao analisar o acórdão do Recurso Especial n ${ }^{\circ}$ 1.704.520/MT, o qual fixou a tese jurídica da taxatividade mitigada do rol de hipótese de interposição de agravo de instrumento, observar, também, as situações fáticas do caso concreto que ensejaram a fixação do supracitado entendimento. Trata-se de um recurso especial interposto contra acórdão prolatado pelo Tribunal de Justiça de Mato Grosso (TJ/MT), o qual negou o provimento ao agravo interno de forma a manter a decisão unipessoal que não conheceu do agravo instrumento interposto por Quim Comércio de Vestuário Infantil LTDA - ME.

É dificultoso extrair todas as circunstâncias fáticas do caso concreto através da leitura do acórdão, uma vez que o mesmo se ateve à problemática envolvendo a interpretação do rol do artigo 1.015 do CPC, de forma a elaborar uma decisão que fixa-se uma tese para ser utilizada em casos futuros o que, novamente, é um dos problemas no manejo dos padrões decisórios. Nada obstante, observa-se que a lide em questão trata de um caso envolvendo a discordância de um decisão interlocutória de primeira instância na qual foi acolhida a exceção de incompetência ofertada pela parte ora recorrida, qual seja, Shirase Franquias e Representações LTDA, de forma a determinar a remessa do processo à comarca do Rio de Janeiro, justificando-se pelo fato de que o juízo de primeiro grau entendeu que inexiste nulidade na cláusula de eleição de foro prevista no contrato de franqueamento celebrado entre as partes.

Nesse sentido, a recorrente Quim Comércio de Vestuário Infantil LTDA - ME fundamentou a interposição do recurso de agravo de instrumento contra a supracitada decisão interlocutória do juízo de primeiro grau em uma interpretação extensiva do inciso III do rol do artigo 1.015 do CPC, o qual prevê que é cabível recurso de agravo de instrumento contra decisão interlocutória que versar sobre a "rejeição da alegação de convenção de arbitragem".

$\mathrm{O}$ voto da ministra relatora Nancy Andrighi foi no sentido de conhecer e dar provimento ao recurso especial, de forma a fixar a tese da interpretação extensiva do rol do artigo 1.015, o qual teria a natureza de "taxatividade mitigada" pois, apesar de admitir a interpretação extensiva, apenas admite-se na hipótese em que ficar constatado a existência 
da urgência e do risco de inutilidade do julgamento da questão a posteriori. A ratio decidendi do voto da ministra relatora, o qual foi vencedor, está na constatação de que é unanimidade na doutrina o entendimento de que o rol das hipóteses de interposição do recurso de agravo de instrumento é insuficiente; para além disso, a decisão fundamentou-se, também, no temor de que o remédio constitucional do mandado de segurança venha a ser utilizado de forma indiscriminada contra decisões interlocutórias, como alternativa à insuficiência do rol do artigo 1.015.

Entretanto, a fixação de tal tese, que já nasce com um status de padrão decisório vinculante, uma vez que foi firmada em sede de recurso especial repetitivo, o qual possui em sua operacionalidade o contraditório diferido que confere o status de vinculação ao padrão decisório, é extremamente problemática. Isso se justifica porque fica claro, inclusive através da leitura do acórdão, que foi uma intenção do legislador a limitação das hipóteses de interposição do recurso de agravo de instrumento e, dessa forma, apenas seria possível a mudança do artigo 1.015 do CPC através de iniciativa legislativa; além disso, a tese fixada, ao fundar-se na "urgência" e na "inutilidade do julgamento da questão no recurso de apelação", promove a abertura de um "gap" ${ }^{50}$, isto é, de uma lacuna na interpretação do artigo 1.015, tendo em vista que os conceitos utilizados como critérios são extremamente subjetivos e, consequentemente, abertos à intepretação. Nesse sentido, a tese fixada promove, também, insegurança jurídica, uma vez que não fica determinado de pronto quais questões são realmente "urgentes" e que, caso não venham a ser recorridas em sede de decisão interlocutória, poderão vir a precluir.

Ressalta-se que não se discorda, aqui, do fato de que realmente o rol do artigo 1.015 do CPC é insuficiente. Nada obstante, essa foi a pretensão do legislador, uma vez que as hipóteses de decisões interlocutórias impugnáveis através do recurso de agravo de instrumento estão minudenciadas no CPC no art. 1.015, principalmente, ao passo em que as

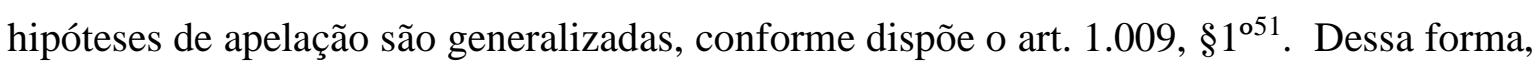
verifica-se que a intenção do Poder Legislativo foi a de que a recorribilidade imediata das

\footnotetext{
50 O substantivo "gap" em inglês denota uma quebra de continuidade e significa, em tradução livre, "lacuna", "vão" ou "abertura".

${ }^{51}$ STRECK, Lenio Luiz; SOUSA, Diego Crevelin. No STJ, taxatividade não é taxatividade? Qual é o limite da linguagem? In: Revista Consultor Jurídico. São Paulo: 07. ago. 2018. Disponível em: <https://www.conjur.com.br/2018-ago-07/stj-taxatividade-nao-taxativa-qual-limite-linguagem\#_ftn4>. Acesso em 29. jul. 2020.
} 
decisões interlocutórias seja a exceção. Destarte, compreender que o rol de hipóteses de interposição de agravo de instrumento é taxativo é a solução íntegra e coerente no contexto do $\mathrm{CPC} / 2015^{52}$.

O voto da ministra relatora, ao contrariar claramente a intenção do legislador e violar o dever de integridade, pode ser caracterizado como ativista, ou seja, configura uma postura contundente do judiciário com o fim de se resolver um problema que não conta uma solução adequada por parte do Poder Legislativo ${ }^{53}$. Destarte, ao praticar uma atuação ativista, o Superior Tribunal de Justiça usurpa de um poder criativo que, apesar de justificar-se no sentido de valorizar o compromisso com a jurisdição ao "solucionar" o problema do rol taxativo do artigo 1.015 do CPC, não é legítimo e constitucionalmente adequado ${ }^{54}$.

Outrossim, compreender que o rol do artigo 1.015 do CPC é taxativo não impossibilita, ao seu turno, a utilização de uma interpretação extensiva. Isso porque a intepretação extensiva dever abarcar o gênero e, consequentemente, outros subtipos do mesmo tipo a que se refere a letra da lei, de forma que esta está submetida ao juízo da agregação no sentido de que o que vale para a parte deve valer, igualmente, para o todo ${ }^{55}$. Destarte, a intepretação extensiva pode ocorrer na medida em que se limita a incluir no conteúdo da norma um sentido que já a pertencia, mas não fora constado de forma expressa pelo legislador ${ }^{56}$.

Entretanto, no que tange o inciso III do artigo 1.015 do CPC, não é admissível a intepretação extensiva pois existe uma distinção crucial entre os conceitos de "arbitragem" e "competência", motivo pelo qual não é possível equipará-los. A diferença está no fato de que a arbitragem consiste em um fato jurídico de investidura jurisdicional, ou seja, quando convenciona-se a arbitragem é outorgado para o árbitro a jurisdição ${ }^{57}$.

52 STRECK, Lenio Luiz; SOUSA, Diego Crevelin. No STJ, taxatividade não é taxatividade? Qual é o limite da linguagem? In: Revista Consultor Jurídico. São Paulo: 07. ago. 2018. Disponível em: <https://www.conjur.com.br/2018-ago-07/stj-taxatividade-nao-taxativa-qual-limite-linguagem\#_ftn4>. Acesso em 29. jul. 2020.

53 RAMOS, Glauco Gumerato. Ativismo e garantismo no processo civil: apresentação do debate. Revista MPMG Jurídico. Belo Horizonte, nº 18, out./nov./dez. de 2009. p. 9.

${ }^{54}$ RAMOS, Glauco Gumerato. Ativismo e garantismo no processo civil: apresentação do debate. Revista MPMG Jurídico. Belo Horizonte, nº 18, out./nov./dez. de 2009. p. 9.

${ }^{55}$ SOUSA, Miguel Teixeira de. Introdução ao Direito. Reimpressão. Coimbra: Almedina, 2013. p. 375.

${ }^{56}$ FERRAZ JUNIOR, Tercio Sampaio. Introdução ao estudo do direito: técnica, decisão, dominação. $8^{\mathrm{a}}$ ed. São Paulo: Atlas, 2015. p. 260.

${ }^{57}$ STRECK, Lenio Luiz; SOUSA, Diego Crevelin. No STJ, taxatividade não é taxatividade? Qual é o limite da linguagem? In: Revista Consultor Jurídico. São Paulo: 07. ago. 2018. Disponível em: 
Nesse sentido, observa-se que a jurisdição possui a natureza jurídica de "poderdever", ao passo em que a competência consiste na fixação de limites para o exercício de tal poder. Destarte, o que se "reparte" é a competência e não o poder, ou seja, a competência consiste na limitação do exercício da jurisdição ${ }^{58}$. É impossível, portanto, equiparar a arbitragem (que se trata de uma jurisdição) à competência, motivo pelo qual é inviável a interpretação extensiva do inciso III do artigo 1.015 do CPC da forma como é pretendida.

Ante todo o exposto, fica constatado que a fixação da tese da taxatividade mitigada do rol do artigo 1.015 do CPC em sede de recurso especial repetitivo, o qual consiste em um padrão decisório com força vinculante, ou seja, é uma decisão judicial deverá ser respeitada por todos os tribunais do país, representa um gap e, também, um duro golpe na coerência e integridade do ordenamento jurídico pátrio, violando diretamente a disposição do artigo 926 do Código de Processo Civil.

\section{TÉCNICAS PARA SUPERAÇÃO E DISTINÇÃO DOS PADRÕES DECISÓRIOS (DISTINGUISHING E OVERRULING)}

Constatado o fato de que, infelizmente, os padrões decisórios poderão vir a ser manejados de forma a romper com a história institucional e violar os deveres de integridade e coerência, faz-se necessário compreender as técnicas utilizadas para proporcionar a superação e a distinção dos mesmos. Observa-se que, mesmo no sistema anglo-saxão, no qual é estabelecida a doutrina do stare decisis, sempre existiu preocupação para flexibilizar a aplicação dos precedentes, de forma que a vinculação nunca foi imutável ${ }^{59}$.

Os padrões decisórios vinculantes podem vir a ser afastados através do distinguishing, ou seja, quando as circunstâncias do caso que deu origem ao padrão decisório forem diferentes do caso a ser julgado. Sendo as circunstâncias análogas, o novo caso será necessariamente decidido com a aplicação dos fundamentos determinantes do padrão outrora

<https://www.conjur.com.br/2018-ago-07/stj-taxatividade-nao-taxativa-qual-limite-linguagem\#_ftn4 >. Acesso em 29. jul. 2020.

58 STRECK, Lenio Luiz; SOUSA, Diego Crevelin. No STJ, taxatividade não é taxatividade? Qual é o limite da linguagem? In: Revista Consultor Jurídico. São Paulo: 07. ago. 2018. Disponível em: <https://www.conjur.com.br/2018-ago-07/stj-taxatividade-nao-taxativa-qual-limite-linguagem\#_ftn4 >. Acesso em 29. jul. 2020.

${ }^{59}$ CÂMARA, Alexandre Freitas. Levando os padrões decisórios a sério. $1^{\text {a }}$ edição. São Paulo: Atlas, 2018. p. 21. 
fixado. Ademais, o padrão decisório vinculante também poderá ser afastado através de overruling, ou seja, quando o próprio tribunal que fixou o padrão decisório vinculante já não o utiliza mais.

Destarte, elucida-se que a distinção (distinguishing) ocorre na hipótese em que o órgão jurisdicional, diante da análise do caso concreto, entende que este possui particularidades que merecem tratamento diferenciado em relação ao caso paradigma ${ }^{60}$. Fazse necessário ressaltar, também, que a utilização da distinção não é uma forma de se deixar de aplicar o padrão decisório mas, sim, de respeitá-lo, tendo em vista que se busca delimitar com precisão em que casos seus fundamentos determinantes deverão incidir ${ }^{61}$.

A superação (overruling), ao seu turno, refere-se às modificações sociais ou jurídicas, como é o caso da modificação substancial da intepretação de uma norma decorrente de alterações econômicas, políticas ou sociais, que impactam diretamente o padrão decisório outrora estabelecido ${ }^{62}$. A importante diferença existente entre as supracitadas técnicas consiste no fato de que na distinção o padrão decisório continua válido, somente não se aplica ao caso concreto tendo em vista as distinções fáticas; ao passo em que na superação o padrão decisório perde a validade, uma vez que não mais coaduna com a realidade jurídica ou social. Destarte, enquanto a superação é utilizada para adequar o padrão decisório, a superação é utilizada como um "modelo de evolução do direito"63.

Necessário salientar, também, que pode ocorrer variação na superação (overruling) levando em consideração a existência de dois tipos de padrões decisórios distintos, quais seja, os vinculantes e os argumentativos, também chamados de persuasivos. Nesse sentido, observa-se que no caso dos padrões decisórios meramente persuasivos, não há restrições relevantes que impeçam a revisão da tese jurídica outrora firmada, ao passo em que no caso dos padrões decisórios formalmente vinculantes a alteração da tese é vista como um

${ }^{60}$ NUNES, Dierle; FREITAS, Marina Carvalho. A necessidade de meios para superação dos precedentes. Revista de Processo. São Paulo, v. 281, jul./2018. p. 13.

${ }^{61}$ CÂMARA, Alexandre Freitas. Levando os padrões decisórios a sério. $1^{\text {a }}$ edição. São Paulo: Atlas, 2018. p. 290.

${ }^{62}$ NUNES, Dierle; FREITAS, Marina Carvalho. A necessidade de meios para superação dos precedentes. Revista de Processo. São Paulo, v. 281, jul./2018. p. 13.

${ }^{63}$ BAHIA, Alexandre; SILVA, Diogo Bacha e. O novo CPC e a sistemática dos precedentes: para um viés crítico das reformas processuais. Direito, Estado e Sociedade, v. 46, p. 55, 2015. Disponível em: 〈www.jur.pucrio.br/revistades/index.php/revistades/article/view/455>, acesso em 28. jul. 2020. 
relevante evento político e jurídico, tendo em vista que poderá vir alterar a compreensão do ordenamento jurídico de forma contundente ${ }^{64}$.

Conquanto a aplicação dos padrões decisórios não pode vir a ser considerada "mecânica" ou "automática", observa-se que existe uma exigência de uma etapa pósinterpretativa, na qual será ajustado o resultado da interpretação do padrão decisório em relação às circunstâncias do caso concreto que agora se analisa ${ }^{65}$. Impende, portanto, ao aplicar os padrões decisórios em caso posteriores, analisar as circunstâncias com o fim de se constatar a necessidade de uma possível distinção ou superação dos mesmos.

Nesse sentido, necessário constatar que, dado o fato de que o dever do ônus argumentativo é nitidamente maior a partir da adoção da sistemática de padrões decisórios pelo CPC/2015, faz-se necessário para o advogado, desde o momento da petição inicial, indicar a existência de padrões decisórios sobre a temática da lide que se discute e, desde pronto, lançar mão da técnica da distinção de forma a viabilizar, do ponto de vista argumentativo, que as individualidades do caso do padrão decisório e do caso concreto que se discute não sejam esquecidas ${ }^{66}$.

\section{CONSIDERAÇÕES FINAIS}

Através da análise desenvolvida no presente ensaio, pôde-se constatar que não existe, no Brasil, um "sistema de precedentes", pois a utilização do termo "precedente" não é feita no sentido técnico da palavra. Existe, portanto, uma sistemática de provimentos vinculantes, que aqui chamamos de "padrões decisórios", os quais podem ser compreendidos como um conjunto de decisões judicias e de súmulas que possuem a predisposição para vinculação, existindo, também, um grupo que possui uma vinculação meramente argumentativa. Além disso, o manejo e a aplicação prática dos padrões decisórios deverão ocorrer de forma a obedecer aos deveres da integridade e coerência, dispostos no artigo 926 do CPC, no sentido

\footnotetext{
${ }^{64}$ VIANA, Antônio Aurélio de Souza. NUNES, Dierle. Precedentes: a mutação no ônus argumentativo. Rio de Janeiro: Forense, 2017. p. 382.

${ }^{65}$ CÂMARA, Alexandre Freitas. Levando os padrões decisórios a sério. $1^{\text {a }}$ edição. São Paulo: Atlas, 2018. p. 288.

66 VIANA, Antônio Aurélio de Souza. NUNES, Dierle. Precedentes: a mutação no ônus argumentativo. Rio de Janeiro: Forense, 2017. p. 382.
} 
de manter a história institucional, através da autorreferência das decisões judiciais, preceitos materializados na metáfora do "romance em cadeia" de Ronald Dworkin.

Por tudo isso, conclui-se que a decisão do Superior Tribunal de Justiça no acórdão do REsp 1.704.520/MT se trata de um "gap", ou seja, de uma quebra de continuidade do romance em cadeia, uma vez que, ao atuar de forma ativista, os ministros violaram diretamente o princípio da integridade. Além disso, a fixação da tese da "taxatividade mitigada" representa, também, um retrocesso na interpretação do artigo 1.015 do CPC, tendo em vista que os critérios estabelecidos para permitir a ampliação do rol de hipóteses de interposição do recurso de agravo de instrumento, quais sejam, a "urgência" e o "risco da inutilidade do julgamento da questão no recurso de apelação", são conceitos totalmente abstratos e abertos à interpretação.

Destarte, o acórdão do REsp 1.704.520/MT promoveu insegurança jurídica, indo na contra mão da pretensão principal da adoção de padrões decisórios no Brasil, uma vez que não restou claro e delimitado quais questões jurídicas poderão ser de pronto agravadas e, portanto, poderão vir a precluir em sede recursal de apelação.

Ademais, ficou constatado, também, que os padrões decisórios não vinculam de forma "mecânica" ou "subsuntiva", fazendo-se fortemente necessária a análise fática dos mesmos a fim de que se verifique a possibilidade de distinção e superação, de forma que a fixação de um padrão decisório jamais poderia colocar a tese jurídica firmada em um patamar imutável.

\section{REFERÊNCIAS}

BAHIA, Alexandre; SILVA, Diogo Bacha e. O novo CPC e a sistemática dos precedentes: para um viés crítico das reformas processuais. Direito, Estado e Sociedade, v. 46, p. 55 , 2015. Disponível em: <www.jur.pucrio.br/revistades/index.php/revistades/article/view/455>, acesso em 28. jul. 2020.

BRASIL, Lei no 13.105, de 16 de março de 2015 - Código de Processo Civil. Disponível em: $\quad$ http://www.planalto.gov.br/ccivil_03/_ato2015-2018/2015/lei/113105.htm, acesso em 29. jul. 2020. 
BRASIL. Superior Tribunal de Justiça. Recurso Especial $\mathrm{n}^{\mathrm{o}} 1.704 .520$ - MT (2017/0271924-6). Min Rel. Nancy Andrighi. DJe: 19/12/2018. Disponível em: $<$ https://ww2.stj.jus.br/processo/revista/documento/mediado/?componente=ITA\&seq $\underline{\text { uencial }=1731786 \& \text { num_registro }=201702719246 \& \text { data }=20181219 \& \text { formato }=P D F}>$. Acesso em 29. jul. 2020.

CÂMARA, Alexandre Freitas. Levando os padrões decisórios a sério. 1. Ed. São Paulo: Atlas, 2018.

DIDIER JR, Fredie. SOUZA, Marcus Seixas. O respeito aos precedentes como diretriz histórica do direito brasileiro. Revista de Processo Comparado. Ano 1, vol. 2, jul.dez./2015.

DWORKIN, Ronald. O império do direito. Trad. Bras. Jefferson Luiz Camargo. São Paulo: Martins Fontes, 1999.

, Ronald. Uma questão de princípio. Trad. Bras. De Luís Carlos Borges. 2. Ed. São Paulo: Martins Fontes, 2005.

FERRAZ JUNIOR, Tercio Sampaio. Introdução ao estudo do direito: técnica, decisão, dominação. 8. Ed. São Paulo: Atlas, 2015.

NOGUEIRA, Gustavo Santana. Stare decisis et non quieta movere: a vinculação aos precedentes no direito comparado e brasileiro. Rio de Janeiro: Lumen Juris, 2011.

NUNES, Dierle; FREITAS, Marina Carvalho. A necessidade de meios para superação dos precedentes. Revista de Processo. São Paulo, v. 281, jul./2018.

RAMOS, Glauco Gumerato. Ativismo e garantismo no processo civil: apresentação do debate. Revista MPMG Jurídico. Belo Horizonte, nº 18, out./nov./dez. de 2009, p. 815.

SOUSA, Miguel Teixeira de. Introdução ao Direito. Reimpressão. Coimbra: Almedina, 2013.

STRECK, Lenio. ABBOUD, Georges. O que é isto - o precedente judicial e as súmulas vinculantes? 3. Ed. Porto Alegre: Livraria do Advogado Editora, 2015.

, Lenio Luiz. Precedentes judiciais e hermenêutica. 2. Ed. Salvador: JusPodivm, 2019. 
, Lenio Luiz; RAATZ, Igor; MORBACH, Gilberto. Da complexidade à simplificação na identificação da ratio decidendi: será mesmo que estamos a falar de precedentes no Brasil? Revista Jurídica Unicuritiba. Curitiba, v. 01, nº 54, 2019.

, Lenio Luiz; SOUSA, Diego Crevelin. No STJ, taxatividade não é taxatividade? Qual é o limite da linguagem? In: Revista Consultor Jurídico. São Paulo: 07. ago. 2018. Disponível em: <https://www.conjur.com.br/2018-ago-07/stj-taxatividade-naotaxativa-qual-limite-linguagem\#_ftn4>. Acesso em 29. jul. 2020.

, Lenio Luiz; SOUSA, Diego Crevelin; GOUVEIA FILHO, Roberto Campos. Por que o STJ deve rever a decisão sobre a taxatividade do artigo 1.015. In: Revista Consultor Jurídico. São Paulo: 13. ago. 2018. Disponível em: 〈https://www.conjur.com.br/2018-ago-13/stj-rever-decisao-taxatividade-11015>.

Acesso em 29. jul. 2020.

TARUFFO, Michele. Precedente e jurisprudência. Trad. Chiara de Teffé. Civilistica.com. Rio de Janeiro, a. 3, n. 2, jul.-dez./2014.

VIANA, Antônio Aurélio de Souza. NUNES, Dierle. Precedentes: a mutação no ônus argumentativo. Rio de Janeiro: Forense, 2017.

, Antônio Aurélio de Souza Viana. Precedentes vinculantes e cortes supremas: uma análise crítica. Teoria Jurídica Contemporânea. Rio de Janeiro, v. 1, n. 2, jul-dez 2016. 